\title{
Sociología y regímenes autoritarios. La Carrera de Sociología de la UBA y los circuitos académicos alternativos durante los "años de plomo"
}

Sociology and Authoritarian Regimes. The Bachelor's Degree Program of the UBA and the alternative academic circuits during the "años de plomo"

Juan Pedro Blois

CONICET - Universidad Nacional de General Sarmiento, [1rgentina $\square$

pedro.blois@gmail.com

\section{Resumen:}

Este artículo busca analizar el desarrollo de la sociología argentina durante el período iniciado a mediados de 1974 con la intervención represiva de las universidades y continuado luego por la dictadura militar. Con base en una perspectiva sociohistórica, el artículo hace foco en lo ocurrido en la carrera de Sociología de la Universidad de Buenos Aires (UBA) y en las principales instituciones alternativas: los centros de investigación privados y las universidades privadas. El análisis, basado en distintos materiales documentales y entrevistas, procura dar cuenta de los efectos del contexto represivo en la práctica de la sociología y sus instituciones. Se mostrará cómo las dificultades para llegar a públicos o clientelas más amplios impulsaron el desarrollo de una sociología crecientemente "ensimismada", cuya relevancia o pertinencia social no siempre resultaba clara para sus propios cultores. Palabras Clave: Sociología, Regímenes autoritarios, Dictaduras, Universidad de Buenos Aires, Argentina.

\section{ABSTRACT:}

This article seeks to analyze the development of Argentine sociology during the period started in 1974 with the repressive intervention of the universities, and then continued by the last military dictatorship. Based on a socio-historical perspective, the article focuses on the University of Buenos Aires' Bachelor's Degree Program and the main alternative institutions: the private research centers and the private universities. The analysis, based on different documents and interviews, tries to account for the effects of the repressive context in the practice of sociology and its institutions. It will be shown that the increasing difficulties in reaching broader publics or clienteles fostered the development of a more "self-referential" sociology, whose social relevance or utility were not always clear to their practitioners.

KEYWORDS: Sociology, Authoritarian Regimes, Dictatorship, University of Buenos Aires, Argentina.

\section{INTRODUCCIÓN}

La creación de la carrera de Sociología de la Universidad de Buenos Aires (UBA) en 1957 fue parte de la oleada de renovación de las ciencias sociales que se dio en la región latinoamericana a partir de la posguerra. Esa oleada estaba motorizada por un diagnóstico que veía en la sociología y las ciencias sociales un insumo fundamental para las tareas que los gobiernos debían encarar en pos de superar el "subdesarrollo" (Blanco, 2006). Inspirados en ese diagnóstico, quienes se hicieron cargo de la nueva institución, entre los que se destacaba el sociólogo italiano Gino Germani, pusieron en marcha una empresa que en un breve lapso concitó el interés de un buen número de estudiantes, pero también una creciente visibilidad pública en tanto voz novedosa -y pretendidamente científica- del campo intelectual (Germani, 2004; Neiburg, 1998; Rubinich, 2010). Posteriormente, a medida que la comunidad sociológica crecía y el proceso de politización y activación social abarcaba a crecientes franjas del mundo universitario, la sociología fue ampliando su público entre quienes eran atraídos por una disciplina que, en la voz de buena parte de sus practicantes, se planteaba como un insumo central en la promoción de cambios de tipo revolucionario. La carrera fue entonces uno 
de los espacios principales de irradiación del conjunto de ideas y prácticas asociadas a una nueva izquierda (Rubinich, 1999; Sidicaro, 1993).

Los cambios en el escenario político impuestos a mediados de 1974 por el giro represivo del gobierno peronista y consolidados luego por el gobierno militar se tradujeron, como se podría esperar, en una violenta intervención en la carrera. La visibilidad ganada en los años previos, así como su identificación con la "subversión" que las nuevas autoridades se proponían ahora desterrar, motivaron una serie de iniciativas que alteraron de modo radical sus principales orientaciones. Luego de permanecer cerrada durante algunos cuatrimestres, la carrera fue reabierta en condiciones irreconocibles, con un cuerpo de profesores poco especializado, con una merma notable del número de estudiantes y bajo la estrecha vigilancia de las autoridades policiales. Semejante ruptura no demoró en afectar severamente el lugar central que este espacio de formación había tenido en el escenario más general de la sociología argentina.

Pero el nuevo contexto no afectaba solamente a esta institución. Varias de las carreras creadas en los años previos en universidades privadas y en el interior del país fueron cerradas (Liedke Filho, 1991). Por su parte, los centros privados de investigación,que se venían multiplicando a raíz de las dificultades para desarrollar tareas de investigación en las universidades (Brunner y Barrios, 1987), continuaron sus labores pero sólo pudieron hacerlo en el marco de un bajo perfil que no atrajera la atención de las autoridades estatales (Sábato, 1996). En ese marco, sus lazos con los pares y fundaciones filantrópicas del exterior se estrecharon, lo que les ofrecía recursos económicos y apoyo simbólico. Sin embargo, ante la falta de públicos o clientelas locales interesados en su producción, sus grados de dependencia externa se incrementaban (Beigel, 2010; Morales Martín y Algañaraz, 2016), lo que hacía que muchas veces su funcionamiento se asemejara a aquel propio de los enclaves económicos: espacios fuertemente integrados en el mercado (académico) mundial pero escasamente conectados con la sociedad donde estaban situados.

Así, de una situación signada por la proliferación de instituciones de docencia e investigación y por una visibilidad creciente de la disciplina en el campo intelectual y el espacio público, se pasó de manera abrupta a una situación en la que la sociología se volvía crecientemente marginal y en la que el trabajo de buena parte de sus practicantes debía desarrollarse dificultosamente en los intersticios de un ambiente intelectual y universitario fuertemente afectado por los embates de las autoridades políticas. De modo similar a lo que paralelamente ocurría en otros países de la región, como Chile o Uruguay, la sociología argentina vivía una fase de clara retracción y repliegue, o en los términos de Trindade, un severo proceso de "desinstitucionalización" (Trindade, 2007).

Este artículo se propone analizar el desarrollo de la sociología argentina durante los llamados “años de plomo" haciendo foco en la carrera de Sociología de la UBA y en las instituciones alternativas que se dinamizaron como respuesta a lo ocurrido en aquel espacio. Si bien existe un conjunto creciente de estudios sobre este período (entre otros: Algañaraz, 2013; Apaza, 2008; Brunner y Barrios, 1987; Casco, 2008; Morales Martín y Algañaraz, 2016; Perel et al., 2006; Raus, 2007; Rodríguez, 2015b), se trata de una fase relativamente poco abordada, sobre la que aún no se ha intentado una mirada de conjunto. Tal vez, tal como es moneda corriente frente a los episodios dictatoriales que bloquean el desarrollo de las ciencias sociales (Kirtchik y Heredia, 2015), quienes se han dedicado al estudio de la historia de la disciplina en la Argentina asumen, como sus colegas de otras latitudes, a los años signados por la represión como una etapa improductiva, un paréntesis que no merecería un estudio más detallado. Sin embargo, la degradación material y simbólica sufrida por la carrera, y en general por la disciplina a partir de mediados de los años setenta, es una parte constitutiva -y clave- de su historia, un punto de inflexión con efectos decisivos en su trayectoria posterior (Blois, 2009).

Este trabajo está basado en distintos materiales documentales (programas de las materias, planes de estudio, publicaciones de la carrera de Sociología de la UBA y de los centros privados de investigación, actas del Consejo Directivo de la Facultad de Filosofía y Letras, y del Rectorado), así como en entrevistas realizadas por el propio autor y otras disponibles en publicaciones y archivos (como el Archivo de Historia Oral del "Centro 
de Documentación Universidad y Dictadura” de la Facultad de Filosofía y Letras de la UBA). Además de esta introducción, el artículo se organiza en cuatro secciones. La primera aborda el período iniciado en 1973 con la llegada del peronismo al poder y sus efectos en la carrera. Su inclusión en el análisis es necesaria, ya que varias de las iniciativas que fueron tomadas posteriormente constituían reacciones directas a lo ocurrido en ese tumultuoso período. La segunda sección examina las reformas introducidas en la carrera en el contexto de la represión y el ascenso del autoritarismo. A continuación, el tercer apartado aborda el accionar de las instituciones no estatales de investigación y enseñanza, prestando particular atención a lo ocurrido en los centros privados de investigación, las universidades privadas y el Colegio de Graduados de Sociología (CGS), una organización creada en 1975. El artículo se cierra con unas reflexiones finales sobre el impacto de la represión y la persecución política en la disciplina y sus instituciones.

\section{EL REgReSo DEL PERONISMO AL PODER Y LA REESTRUCTURACión DE LA CARRERA DE LA} UBA

La llegada de Héctor Cámpora al poder constituyó, sin dudas, un punto de fuerte inflexión en el clima político general. Como es sabido, la dictadura iniciada en 1966 debió abandonar el poder jaqueada por la movilización popular y la presión de las organizaciones armadas, lo que dio inicio a un tan agitado como breve período democrático. Algunos sectores de la juventud peronista, que expresaban a las vertientes más radicalizadas de ese movimiento político, llegaron a posiciones clave: la gobernación de varias provincias, algunos ministerios y, last but not least, el control de las universidades más importantes (Buchbinder, 2005, Friedemann, 2017, Rodríguez, 2015a). Poco tiempo después de asumir, el nuevo presidente decretó la intervención en las universidades.

Al frente de la UBA, rebautizada ahora como Universidad Nacional y Popular de Buenos Aires, fue designado Rodolfo Puiggrós quien, con el sostén de buena parte del peronismo de izquierda, proyectó una profunda transformación de sus estructuras administrativas y curriculares. Esa transformación buscaba clausurar una historia en la que la universidad -según las nuevas autoridades- había sido funcional a los intereses de los "poderosos", y ponerla por primera vez al servicio de la "liberación nacional" y del "pueblo". En su visión, las casas de altos estudios debían conformar el centro de una auténtica "revolución cultural" (Buchbinder, 2005, p. 199) en el que las iniciativas simbólicas tendientes a recuperar algunas de las figuras emblemáticas de la tradición "nacional” y "popular" ocuparan un lugar central. Diversas personalidades, que incluían desde Eva Perón a Enrique Santos Discépolo, pasando por Raúl Scalabrini Ortiz, John William Cooke y Leopoldo Marechal, fueron nombradas como profesores eméritos post mortem (Mallimaci y Georgi, 2007). La editorial Eudeba fue confiada a Arturo Jauretche, quien promovió una renovación del catálogo que buscaba dar más lugar a la producción local y latinoamericana, y que no rehuía una explícita toma de posición política e ideológica.

En la Facultad de Filosofía y Letras (FFyL) se designó a Justino O’Farrell como decano interventor. Este sociólogo había sido una de las principales figuras de las llamadas "cátedras nacionales", un conjunto de materias que desde una explícita identificación con el peronismo había promovido una mayor conexión de la disciplina con la práctica política en los años previos ${ }^{1}$. La llegada de O’Farrell al decanato era parte de un movimiento más amplio que concedió espacios de responsabilidad institucional a buena parte de los miembros de las "cátedras nacionales" (Friedemann, 2017; Rubinich, 1999).

El nuevo contexto, como podría preverse, indujo una serie de reacomodamientos y cambios en la carrera de Sociología. Su dirección fue inicialmente confiada a Fernando Álvarez y la subdirección a Susana Checa, dos jóvenes graduados identificados con las cátedras nacionales, que rápidamente procedieron a reformular el plantel docente. Mientras algunos profesores eran desplazados de manera sumaria, otros, con buena llegada a las nuevas autoridades y declarada simpatía por el flamante gobierno, consiguieron un lugar en el renovado plantel docente. Pero la vocación transformadora no se limitaba a la composición del plantel docente. Las 
nuevas autoridades impulsaron una modificación del plan de estudios con la intención de propiciar una integración mayor de las materias y sus contenidos con el proceso de "liberación" que parecía en marcha. Para ello, el nuevo plan, aprobado a principios de 1974 , buscaba "privilegiar un conjunto de materias orientadas a dotar al egresado de un conocimiento adecuado de la realidad nacional, sus orígenes históricos y su contexto internacional", al mismo tiempo que pretendía "incorporar áreas de especialización que favorezcan no sólo la inserción laboral del egresado sino su utilidad como profesional en la presente etapa" (Plan de estudios de la carrera de Sociología, 1974).

Lo primero, el énfasis en el conocimiento histórico de la propia realidad recogía el acento que en el período anterior las "cátedras nacionales" habían puesto sobre el estudio de la historia local y de las relaciones internacionales de nuestro país. De hecho, las materias obligatorias que creaba el plan se distribuyeron entre tres reconocidos promotores de una "sociología nacional": Ernesto Villanueva se hizo cargo de Análisis de la sociedad argentina I (1880-1943); Juan Pablo Franco, quien por entonces era el director del Instituto de Sociología, de Análisis de la sociedad argentina II (1943-1955), y el ya mencionado Fernando Álvarez, de Análisis de la sociedad argentina III (1955 a la actualidad).

Lo segundo, la preocupación por la "utilidad" de la sociología era parte del espíritu más general que recorría la universidad en la nueva hora, tendiente a reformular su papel y estrechar sus vínculos con la sociedad (Buchbinder, 2005; Friedemann, 2017). Si en el pasado no habían sido pocos los reparos que buena parte de los sociólogos tenían contra la inserción en la burocracia pública (Blois, 2016, 2017), ahora, con un gobierno que parecía comprometido con la construcción de un "socialismo nacional”, la situación, al menos para quienes se identificaban con el peronismo, parecía haber cambiado. La carrera podía ahora alentar la participación de sus graduados en el gobierno como "técnicos" o "expertos", sin arriesgar su orientación crítica ${ }^{2}$. La planificación -regional, educativa y sanitaria- cobró entonces una creciente gravitación como área de expertise a ser fomentada ${ }^{3}$.

Ahora bien, a diferencia de lo ocurrido con la intervención de 1966 (Rubinich, 2010), no hubo en rigor una profunda reorientación de los contenidos de la mayoría de las materias ${ }^{4}$. Lejos de ello, los temas que concitaron la atención en esta etapa mantuvieron, tal como se puede apreciar en los programas de las materias, una clara continuidad con el período anterior. La cuestión de la dependencia (económica, política, cultural), la historia de la clase obrera y del sindicalismo argentino, la elaboración de una "sociología nacional", el énfasis en la historia nacional y latinoamericana permanecieron como los focos privilegiados en los intercambios entre docentes y alumnos.

Hubo, sin embargo, una vinculación mucho más directa con la política, vinculación que en algunos casos borró los límites de la sociología con las disputas y posicionamientos directamente ideológicos o partidarios (Rubinich, 1999; Sidicaro, 1993). Resulta una muestra de ello que en ese momento se produce la llegada de un conjunto de docentes sin antecedentes en la disciplina, cuyas credenciales o méritos habían sido acumulados en la militancia dentro del peronismo. Tal es el caso, por ejemplo, de José Fernández Valoni, un joven militar y diputado peronista que desde su materia, Seguridad y defensa nacional, se proponía "destacar la vigencia de la Doctrina Peronista", dando "atención preferente a los escritos estratégicos militares del Tte. Gral. Perón y a las actualizaciones especializadas de cuadros de conducción del MNP [Movimiento Nacional Peronista]". En su materia, en la que parte del material de lectura eran las "20 verdades peronistas", se preveía la invitación de dirigentes y cuadros de ese movimiento para abordar algunas de las temáticas. Algo similar ocurría con Carlos Mazar, uno de los fundadores del Grupo Cine Liberación. Su materia, llamada Seminario de cine y realidad nacional, planteaba al cine como un elemento estratégico en la "formación de la conciencia nacional", y proponía, luego de un repaso por la historia del cine argentino y su dependencia respecto del cine norteamericano, una "teoría y práctica de un cine descolonizado". Entre los trabajos prácticos previstos para aprobar el seminario figuraba la realización de una "encuesta sobre el grado de penetración ideológica en distintas zonas de la ciudad”, la filmación de un cortometraje en $8 \mathrm{~mm}$, así como las proyecciones de películas en barrios populares seguidas de debates ${ }^{5}$. 
En estos casos la asignación de las materias era indisociable de las disputas que se daban entre los grupos políticos que pugnaban por el control de la universidad, siendo el reparto de cargos docentes una expresión directa, casi sin mediaciones, del avance o retroceso de una u otra fracción. Las tomas de posición política pesaron entonces mucho más que las credenciales o titulaciones académicas. Aun cuando en los años anteriores no habían faltado las posiciones que -como las de quienes se identificaban con las cátedras nacionales- impulsaban la dilución de la sociología en la política, lo que ocurría en la carrera no había dejado de inscribirse en un juego relativamente autónomo en el que las apuestas "politizadoras" eran parte de estrategias tendientes a maximizar las posiciones ocupadas en el espacio académico ${ }^{6}$. Ahora, en contraste, la lógica política y partidaria, con sus jerarquías y alineaciones particulares, irrumpía con fuerza en la universidad y redefinía buena parte de las orientaciones que dominaban la carrera.

La efervescencia política y social que animaba al espacio público más amplio era incontenible. Ello era visible en el perfil de los profesores y sus materias pero también en las orientaciones de quienes iban a las clases. La carrera pudo, en ese marco, ampliar de modo notable sus públicos y audiencias. Su identificación y visibilidad como un espacio de perfil contestatario construido en los años previos promovió la ampliación del número de nuevos inscriptos, que aumentó un $50 \%$ y para pasar en solo un año de 1075 a 1542 (Rodríguez Bustamante, 1979). Este incremento estuvo posibilitado por la instauración del ingreso irrestricto y la eliminación del examen de ingreso decidida con la asunción del nuevo gobierno (Rodríguez, 2015a). A ello era preciso sumarle la presencia de un buen número de "oyentes" de mayor edad y muchas veces formados en otras profesiones que, según los testimonios de la época, asistían a las clases de los profesores más reconocidos y prestigiosos de la Facultad (como Juan Carlos Portantiero, Silvio Frondizi o Justino O'Farrell), interesados en escuchar y debatir sobre el presente del país, sin ninguna preocupación por obtener un título universitario. Esto ocurría dado que para buena parte de los docentes y de los alumnos, el ámbito de formación de los sociólogos debía configurarse como un espacio de formación política y militancia.

Dado lo anterior, tal como podría esperarse, la carrera figuró como uno de los blancos principales de la represión desatada en los claustros universitarios a partir de mediados de 1974. Su accionar, continuado luego por la dictadura militar, sentaría las bases de una nueva etapa en la vida de esta institución y, más en general, en el desarrollo de la sociología argentina.

\section{El giro RePresivo y LA ReSTRUCTURACión de LA CARrera}

Con la muerte del Gral. Perón en julio de 1974 se produjo un marcado giro represivo del gobierno nacional, que buscó desarticular de manera violenta (a través de medios legales e ilegales) los focos de resistencia que en su visión promovían un clima de "subversión" e impedían consolidar el orden social. En ese marco, se designó como rector de la UBA a Alberto Ottalagano, un abogado y filósofo peronista con declarada simpatía por el fascismo, que asumió con la misión de desalojar a los sectores de la izquierda peronista de la universidad. Rápidamente, a la expulsión de buena parte de los docentes -varios de los cuales debieron emprender el camino del exilio (Casco, 2015)-, se sumó la instauración de un clima de férrea vigilancia en cada una de las facultades, que incluía la designación de "celadores" (provistos por la policía y las Fuerzas Armadas) encargados de disuadir las actividades políticas de los estudiantes y docentes (Buchbinder, 2005; Rodríguez, 2015a).

En FFyL fue nombrado como decano interventor Raúl Sánchez Abelenda, un sacerdote y profesor de filosofía identificado con los sectores más conservadores del catolicismo. En línea con las orientaciones del Rectorado, el nuevo funcionario se propuso restablecer la "autoridad" y el "orden" a partir de un amplio abanico de medidas: se fijó como una obligación la exhibición de la libreta universitaria para poder acceder a las clases y la presentación de un certificado de "buena conducta" (expedido por la Policía Federal) para poder rendir los exámenes; se prohibió expresamente la organización de actividades extracurriculares (mesas, seminarios, conferencias, etc.) sin autorización previa; se vedó la organización de cualquier tipo de asamblea 
(Friedemann, 2016). Paralelamente, y como respuesta a las orientaciones dominantes en el período anterior, se desarrolló un conjunto de iniciativas simbólicas con una pretensión claramente restauradora. Mientras desde el Rectorado se reintroducía el nombre tradicional de la institución (eliminando la palabra popular), se cambiaba el nombre de algunas dependencias e institutos (que habían sido rebautizados a partir de 1973), y se conmemoraba -dando cuenta de las preferencias ideológicas e intelectuales de quienes controlaban la institución- el séptimo centenario de la muerte de Santo Tomás de Aquino. Por lo demás, lo anterior iba de la mano de una creciente represión ilegal que era avalada por las autoridades universitarias (Mallimaci y Giorgi, 2007).

Más decisivo aún, el nuevo decano promovió el desmembramiento de la Facultad a partir de la separación de las carreras de Sociología, Psicología y Ciencias de la Educación. Esas carreras habían cambiado el perfil tradicional de la Facultad por sus ideas renovadoras y su apertura a nuevos saberes, pero también, y de modo fundamental, por su número de estudiantes que rápidamente superó aquel propio de las carreras tradicionales. En 1972, la suma de esas carreras explicaba casi el 70 \% de la matrícula total de la Facultad ${ }^{7}$ . Esa iniciativa, como las anteriores, buscaba desarticular el clima de agitación que signaba las aulas y pasillo de la institución. En el caso de Sociología, su separación conllevó su organización como una carrera "suelta" directamente dependiente del Rectorado.

La carrera fue emplazada en la Facultad de Derecho y Ciencias Sociales (FDyCS). Su nueva ubicación no conllevaba, con todo, una integración institucional u "orgánica" a esa facultad. Se trataba, antes bien, del préstamo de un espacio en el que poder funcionar, al que las autoridades de esa institución debieron acceder a regañadientes. Como muestra del escaso entusiasmo que les generaba esa incorporación, los recién llegados fueron ubicados en un conjunto de aulas mal iluminadas y de paredes húmedas en el sótano del tradicional edificio. Esas aulas eran conocidas como las "catacumbas" y constituían, como podría anticiparse, un espacio aislado respecto de las actividades desarrolladas a la luz del día. Quedaba claro que para las autoridades de la FDyCS la formación de los sociólogos estaba lejos de tener la misma jerarquía o importancia que la formación de los futuros abogados. La falta de un lugar adecuado donde llevar a cabo las clases y las tareas de investigación no era una novedad para la carrera ${ }^{8}$. Sin embargo, el nuevo emplazamiento exacerbaba ese déficit y mostraba con singular contundencia la escasa valoración que Sociología despertaba en las autoridades universitarias. Su ubicación en un sótano, donde se suele colocar aquello que no es útil o no se desea ver, no podía dejar de conllevar una fuerte degradación simbólica (Raus, 2007).

Inicialmente, durante la intervención encabezada por Ottalagano, la dirección de la carrera fue confiada a Rodolfo Tecera del Franco, un viejo profesor de sociología que se había desempeñado como docente de la cátedra de Sociología y como director del Instituto en la FFyL hasta 1955. Por sus afinidades políticas y teóricas, tanto como por su forma de concebir la sociología, este abogado devenido sociólogo había representado para Germani y sus colaboradores de forma emblemática todo lo que de indeseable y censurable había en la denostada "sociología de cátedra" (Blanco, 2006; Pereyra, 2010). Desplazado de sus inserciones académicas, Tecera del Franco se había dedicado a la política y había llegado a ser diputado nacional entre 1963 y 1966 por una agrupación neoperonista. Sin dudas, sus fluidos contactos con los sectores de la dirigencia peronista más conservadora, que ahora controlaban los resortes de la gestión pública, le facilitaron la llegada a su nuevo cargo.

Desde su flamante posición, Tecera del Franco promovió la creación de una "comisión reorganizadora" encargada de formular un nuevo plan de estudios destinado a reemplazar aquél formulado hacía pocos meses, cuyo tono y fundamentaciones ya no respondían a las orientaciones que se pretendía imponer desde el gobierno. Esa iniciativa respondía a una demanda del Consejo Superior de la Universidad que a comienzos de 1975 pedía una "seria reconsideración" de la carrera y de su plan de estudios ante "el desmoronamiento y la desviación notoria del nivel académico" (Actas del Consejo Superior, 19/2/1975)

Ahora bien, el golpe de Estado de marzo de 1976 motivó la renuncia del Director de la Carrera y su reemplazo por un delegado militar, el capitán de fragata Julio Santoianni, quien de modo preventivo y 
hasta recabar más información prohibió el dictado de clases por parte de los profesores nombrados hasta ese entonces (Rubinich, 2010). Sin embargo, al poco tiempo, los militares cedieron sus posiciones a los civiles y Alberto Constantini asumió como Rector de la UBA. En ese marco, la comisión fue reconfirmada, siendo uno de sus miembros, Carlos Alberto Weiss, designado como delegado del rector en la carrera. Weiss era un abogado que en el pasado había tenido un paso por la carrera como profesor de la materia Propiedad y sociedad: su problemática, entre 1969 y 1972.

En rigor, entre la gestión desarrollada durante el último período del peronismo y aquella que continuó sus actividades a partir de 1976 no hubo discontinuidades. Fue el mismo grupo relativamente reducido de profesores el que controló la institución a lo largo de todo el período (incluso Tecera del Franco no demoró en reincorporarse al plantel docente). Sin dudas, fueron sus iniciativas, así como los contactos que algunos de ellos tenían con las autoridades castrenses -había quienes daban clases en alguna de las escuelas de formación militar-, lo que contribuyó a evitar el cierre de una carrera que, dada la visión negativa que las autoridades militares tenían de su derrotero previo y de las ciencias sociales en general, bien podría haber sido clausurada 9 . Para el grupo de docentes que había llegado a la institución a partir de 1974, la continuidad de ese espacio, ahora "en disponibilidad", abría una interesante oportunidad laboral. La carrera, es cierto, no era el ámbito más dinámico o prestigioso del campo universitario o intelectual, pero para quienes no tenían demasiados antecedentes académicos las retribuciones materiales y simbólicas asociadas a la docencia en la UBA no eran nada desdeñables. En esas condiciones, luego de permanecer algunos cuatrimestres sin clase, la carrera comenzó a funcionar regularmente a partir de $1977^{10}$.

Con todo, los esfuerzos por preservar la institución no suponían una idea muy clara sobre el perfil que la carrera podría tener en la nueva etapa o sobre el papel o funciones que sus estudiantes podrían desarrollar una vez graduados. Como apunta Rubinich, los miembros de la comisión "no contaban con una carrera académica reconocida en la Sociología ni exhibían antecedentes suficientes para una función que, en términos concretos, significaba la reorganización de la Sociología como disciplina universitaria” (Rubinich, 2010, p. 51).

Hubo quienes buscaron justificar la pertinencia de la sociología como una auxiliar técnica de la acción estatal en momentos en que el gobierno decidía la creación de un -fugaz y fallido- Ministerio de Planeamiento. Así, al tiempo que Carlos Weiss en una breve entrevista con la revista Confirmado se mostraba optimista en momentos en que "el propio gobierno aparece interesado en gestar un Ministerio de Planeamiento en el que, sin duda, habrán de requerirse sociólogos de nivel académico óptimo" (citado en Perel, Raíces y Perel, 2006, p. 136), Efrain del Castillo, su sucesor, afirmaba al asumir su cargo que la "labor futura será apoyar firmemente al Ministerio de Planeamiento, porque consideramos imprescindible aplicar aquello de que "hay que prever, para proveer"', anunciando, incluso, la creación de una carrera de Ciencia Política y otra de Administración Superior del Estado, en una nueva Facultad de Ciencias Sociales (citado en Perel, Raíces y Perel, 2006, p.136). Pero esas no eran más que expresiones de deseo: el escaso interés o indiferencia de las autoridades nacionales, que lejos estaban de ver en la sociología un insumo relevante para su proyecto de profunda reorganización política y social, fue una constante del período. La carrera no figuraba entre las instituciones que las autoridades militares impulsaban en el ámbito cultural (Alvárez, 2006) (algo que, por lo demás, el trajinar cotidiano por los penumbrosos sótanos de la FDyCS debía recordar una y otra vez ${ }^{11}$.

Semejante situación contrastaba con lo experimentado por la sociología en otros contextos autoritarios donde el poder político buscó transformar los espacios de investigación y formación propios de la disciplina en polos de irradiación de la doctrina oficial, como, por ejemplo, ocurrió en la URSS durante el stalinismo o en Alemania durante el régimen nazi. Pero también contrastaba con la situación vivida por las ciencias sociales en aquellos regímenes que, como los de los países del este europeo durante la posguerra, financiaban sus actividades para estimular la producción de estudios aplicados (con el fin de asesorar la toma de decisiones) sin dejar, no obstante, ningún margen para la definición de una agenda autónoma de investigación (Kirtchik y Heredia, 2015). En el caso argentino, dada la profunda indiferencia de las autoridades castrenses, una vez 
realizada la "depuración ideológica", no hubo intromisiones a la hora de definir los contenidos, pero tampoco encargos que pudieran estimular la producción de nuevo conocimiento.

En esas condiciones, como es comprensible, el nuevo plan de estudios, con el que serían recomenzadas las clases, no sería más que un listado de materias, sin ninguna fundamentación o explicitación de principios que fuese capaz de dotarlo de una orientación o sentido relativamente definido. Por las mismas razones, el contenido y orientación de cada materia quedó fuertemente condicionado por el perfil de cada docente. Sin una coordinación clara desde la dirección de la carrera, tanto la orientación como la "calidad" de cada materia variaban fuertemente.

Además de la eliminación del vocabulario más explícitamente político que caracterizaba al plan de 1974, se decidió el cese de las materias optativas; se introdujeron materias o áreas que hasta allí no habían sido parte de la formación de los sociólogos -como Introducción al Derecho, Filosofía Social, Filosofía de la Historia, Geopolítica-; se fusionó en un único título la licenciatura y el profesorado de modo tal que todos los estudiantes debían cursar las materias pedagógicas -Psicología de la niñez y la adolescencia, Pedagogía, Didáctica y Práctica de la Enseñanza-, tuvieran o no interés en una formación docente. Antes que opciones de principio o proyecciones de una idea previamente definida, esas iniciativas eran la expresión de una situación en la que los "recursos humanos" mínimamente calificados para hacerse cargo de una cátedra no sobraban. La eliminación de las materias optativas y la obligación de cursar las materias pedagógicas reducían la cantidad de docentes necesarios para el funcionamiento de la carrera, al tiempo que la introducción de materias poco específicas podía justificar la incorporación de docentes de otras especialidades y formaciones, lo que ampliaba el plantel docente.

El cuerpo de profesores se mantuvo relativamente estable a lo largo de todo el período y estaba formado por un conjunto de individuos con trayectorias y antecedentes muy heterogéneos. Salvo algunas excepciones, como las de Roberto Brie o Fernando Cuevillas, la mayoría no había tenido en el pasado ninguna vinculación con la carrera, fuera como profesores o alumnos ${ }^{12}$. Algunos podían mostrar, no obstante, cierta experiencia docente en el área desarrollada en alguna de las cátedras de sociología de las universidades del interior o en las universidades confesionales. Sin embargo, no eran pocos los que "debutaban" en la docencia universitaria, a poco de haberse graduado ${ }^{13}$.

Como se podría prever, en el cuerpo docente no faltaban quienes adherían de modo explícito a las líneas generales del "Proceso", casi siempre desde posiciones nacionalistas y católicas. Pero había también un conjunto de docentes con un perfil "técnico" que, sin definirse políticamente y sin adscribirse necesariamente al régimen, encontraron en el contexto dictatorial, tal como ocurrió en varias dependencias burocráticas (Lvovich, 2009), una oportunidad laboral. Mientras en general estos últimos tuvieron a su cargo las materias metodológicas, los primeros se ocuparon de las materias filosóficas (que habían aumentado en número), en las que no faltó la bibliografía de filiación católica, en algunos casos, combinada con ciertos autores alemanes claramente racistas. Por ejemplo, Héctor Martinotti, un profesor de filosofía proveniente de la Universidad Católica de La Plata (UCALP), incluía como material de lectura de la materia Filosofía Social la obra de Jacques de Mahie, un emigrado francés colaborador del régimen de Vichy, que en el medio local había influido en la agrupación de ultraderecha Tacuara. Para aprobar su materia, sin ánimo de ocultar sus más firmes convicciones, establecía como requisito la elaboración de una monografía que analizara una encíclica papal. Por su parte, Hermes Puyau, un filósofo que había sido decano de la Facultad de Filosofía de la USAL entre 1968 y 1972, y luego nombrado director del departamento de Filosofía de la UBA durante la intervención de Sánchez Abelenda, proponía en Introducción a la Filosofía un recorrido por el pensamiento occidental construido sobre una matriz tomista (Raus, 2007). En general, y salvo alguna excepción puntual, se trataba de figuras de bajo perfil y escaso reconocimiento académico y público. La carrera no era un espacio atractivo para quienes contaran con inserciones alternativas ${ }^{14}$.

Si hay algo que caracteriza a la carrera en este período es el "encapsulamiento" que signó su funcionamiento. Por un lado, la carrera cortó cualquier vinculación con las iniciativas que de modo paralelo se desplegaban 
en el escenario más amplio de la sociología local. Sus profesores y programas tendieron, en efecto, a ignorar todo aquello que se realizaba en los centros privados de investigación (a los que nos referiremos en la próxima sección). Ello, sin dudas, reforzaba la endogamia-no eran inusuales las mutuas referencias a la hora de armar los programas entre los profesores-, pero también debilitaba su reconocimiento como "sociólogos" en el espacio más amplio de la sociología local (Blois, 2009) ${ }^{15}$.

Por otro lado, la carrera cortó las relaciones con su propio pasado, no sólo por la procedencia de la mayoría de sus docentes, sino porque los programas de las distintas materias, salvo excepciones muy puntuales, no incluían los textos de quienes en los períodos anteriores se habían sucedido en la carrera ni las publicaciones y traducciones que, desde 1955, se habían realizado desde la Oficina de Publicaciones de la FFyL ${ }^{16}$. En el pasado, es cierto, no habían faltado los quiebres y las reorientaciones -piénsese en los conflictos de Germani con sus colaboradores o en el enfrentamiento de la "sociología nacional” y su lucha por desplazar al "cientificismo" (Germani, 2004; Ghilini, 2017; Noé, 2005; Rubinich, 1999)-, pero esos quiebres se realizaban desde posturas críticas que tomaban una posición explícita sobre lo realizado hasta entonces. Ahora, en contraste, no se recuperaba nada: la carrera se constituía como una institución sin historia previa. Sin dudas, la expulsión de FFyL, su nuevo emplazamiento físico, así como un clima de cursada que nada tenía que ver con lo vivido en los años previos, reforzaban el quiebre. Por lo demás, los profesores que habían tenido un paso previo en la Carrera, como Brie o Cuevillas, no eran muy proclives a recuperar sus experiencias en una institución en la que, aun ocupando posiciones destacadas, debieron sufrir en carne propia los efectos de un público estudiantil rebelde y contestatario ${ }^{17}$.

Pero esas no fueron las únicas novedades introducidas en este período. Hubo también una marcada y llamativa desconexión de las distintas materias con el análisis de la sociedad contemporánea y de su pasado inmediato. Ello contrastaba fuertemente con lo ocurrido en la etapa anterior, momento en que las problemáticas del momento recibían una decidida atención, pero también con el fuerte énfasis en el estudio del presente que la carrera había mostrado en su momento fundacional (Germani, 2004). En la nueva etapa, por el contrario, la sociología enseñada en la carrera se configuraba como una disciplina desconectada de los dilemas y problemas del presente. Sin dudas, tanto el clima político más general como el perfil libresco o doctrinario de buena parte de los docentes favorecían esa inclinación.

Muestra de ello, las materias centradas en el "análisis de la sociedad argentina" fueron reducidas de tres a dos por el nuevo plan de estudios y sus titulares, historiadores de formación, evitaron en todo momento abordar los procesos más contemporáneos. Aun cuando tuviesen diversas orientaciones, uno de sesgo nacionalista, el otro más liberal, ambos evitaron ir más allá de la etapa previa al primer peronismo.

Algo similar ocurría con las materias de teoría sociológica en las que, salvo contadas excepciones, no había bibliografía que analizara procesos o situaciones más "locales" o "actuales", y en las que, como se podría esperar, no había lugar ya para los autores latinoamericanos ni para la preocupación por la dependencia que había dominado en los años anteriores. Así, aun en una materia como Sociología de la época actual, que, tal como puede constarse en su programa, se proponía abordar la "crisis contemporánea en la Argentina actual", su titular, Tecera del Franco, favorecía una bibliografía que no incluía textos sobre nuestro país ${ }^{18}$.

El nuevo contexto, como se podría anticipar, no podía dejar de afectar el desarrollo de la investigación. En efecto, aun cuando el nuevo plan de estudios mantuvo el requisito de las doscientas horas de investigación -e incluso imponía ahora como requisito la elaboración de una tesis de grado-, la enseñanza en la carrera no perdió por ello su sesgo libresco. Difícilmente podría ser de otro modo si, además del perfil ya mencionado de los profesores, se piensa en el predominio casi absoluto de las dedicaciones simples: casi todos los docentes tenían como ocupación principal un trabajo fuera de la carrera. Por lo demás, resulta interesante destacar aquí que cuando en 1981 se produjo la reactivación del Instituto de Investigaciones, su dirección fue confiada a Tecera del Franco, un sociólogo poco interesado por el desarrollo de las indagaciones empíricas (Raus, 2007) ${ }^{19}$. 
Cabe señalar que la postergación de la investigación que se daba en la carrera estaba en línea con la política científica impulsada por el gobierno militar que desde el inicio de su gestión buscó desplazar las actividades de investigación desde las universidades hacia una serie de institutos dependientes del Conicet, varios de los cuales fueron creados en esos momentos. Las universidades, según se afirmaba, debían estar limitadas a su función "específica": la enseñanza (Bekerman, 2009). Si ello no resultaba problemático para las disciplinas tradicionalmente "profesionalistas", constituía un duro golpe para aquéllas que, como la sociología, habían buscado promover en el pasado una formación en la que la docencia y la investigación debían ir de la mano ${ }^{20}$.

Durante este período, hubo en la carrera una fuerte baja del número de estudiantes, una novedad en el marco de la tendencia de una matrícula que, en el clima de optimismo modernizador primero y de fuerte politización después, se había siempre mostrado ascendente. La caída era notable: mientras que en 1972 había casi 2800 alumnos, en 1980 esa cifra se había reducido a poco más de 500 (Censos de estudiantes, UBA). La baja era de tal magnitud que, aun en el marco de las restricciones a los ingresos dispuestas por el gobierno nacional $^{21}$, el cupo anual habilitado para la carrera no era siempre cubierto.

Varios factores se conjugaron para ello. Por un lado, el clima represivo más general que impactó fuertemente en el seno de una carrera que pasó de modo abrupto de la dinámica asamblearia, que cuestionaba las jerarquías tradicionales y le daba un protagonismo central a las inclinaciones de los estudiantes, a una violenta restauración de los modos más tradicionales y conservadores de enseñanza. Por otro lado, la cesantía y alejamiento de los profesores más reconocidos y el escaso atractivo de la enseñanza ofrecida por sus reemplazantes.

Sin los profesores que en el pasado le habían dado cierta visibilidad y prestigio en el campo universitario e intelectual más general, y con un número de estudiantes en franco retroceso, la gravitación de la carrera en el escenario de la sociología argentina disminuyó marcadamente. En esas condiciones, se produjo una correlativa dinamización de otros ámbitos que, fuera de la órbita estatal y, por lo mismo, menos expuestos al control de las autoridades gubernamentales, sirvieron de "refugio" para buena parte de los sociólogos desplazados de las instituciones oficiales.

\section{LOS CIRCUITOS ALTERNATIVOS: INVESTIGACIÓN Y DOCENCIA EN UN CONTEXTO HOSTIL}

Los centros privados de investigación habían surgido en los años previos como una respuesta a las dificultades que la secular inestabilidad de las instituciones públicas ponía al desarrollo de la sociología y las ciencias sociales en nuestro país (Thompson, 1994). Pese a las agudas polémicas y resistencias suscitadas por sus vinculaciones con las fundaciones norteamericanas (Blois 2016; Gil, 2011), los centros habían podido desarrollar una intensa agenda de investigaciones. Al momento de producirse las intervenciones en la carrera, de 1973 y de 1974, que supusieron por igual el desplazamiento de un buen número de docentes, los centros constituían ya un denso entramado de instituciones, relativamente preservadas de los vaivenes de la política nacional. En ese marco, espacios como el Centro de Estudios Urbanos y Regionales (CEUR), el Centro de Estudios de Población (CENEP), el Centro de Investigaciones sobre el Estado y la Administración (CISEA), el Centro de Estudios de la Sociedad y el Estado (CISEA), el Centro de Estudios de Estado y Sociedad (CEDES) y el Centro de Investigaciones en Ciencias Sociales (CISCO) pudieron ofrecer un ámbito de trabajo a un buen número de sociólogos. En varios casos esos centros habían operado dentro del Instituto Torcuato Di Tella y debieron autonomizarse con la crisis de esa institución. El período inaugurado por el golpe militar de 1976 no haría más que reforzar la función de estas instituciones como espacios donde desarrollar labores de investigación y, en algunos casos, de formación de jóvenes investigadores (Brunner y Barrios, 1987; Morales Martín y Algañaraz Soria, 2016).

El clima de censura, persecución y terror promovido por las autoridades castrenses, sin embargo, afectó fuertemente el trabajo de los centros. Aun cuando sus labores pudieron ser continuadas, el nuevo escenario indujo un claro repliegue de sus actividades, que debieron asumir un perfil más bajo, en particular durante 
los primeros años del nuevo régimen. Esa reserva era parte de una estrategia de supervivencia, pues, según creían sus miembros, una mayor visibilidad podría suscitar la reacción de un gobierno dispuesto a eliminar violentamente toda fuente de disenso o crítica a sus iniciativas (Wainerman, 2015; Vessuri, 1992). El bajo perfil era tal que quienes animaban esas instituciones sentían que participaban de una "universidad de las catacumbas" (Sábato, 1996) 22 .

En ese contexto, el trabajo de los sociólogos de los centros devino crecientemente "ensimismado". Por un lado, las vinculaciones que algunos de ellos en el pasado habían entablado con ciertas dependencias estatales -que habían contratado sus servicios para la realización de estudios y consultorías- fueron abruptamente interrumpidas a partir de las reestructuraciones sufridas por esas instituciones. Por el otro, la llegada a audiencias o públicos más amplios que en algunos casos se había dado a través de sus publicaciones y cursos debió ser reducida a una mínima expresión ${ }^{23}$. Incluso el CICSO, una institución que había evitado el financiamiento externo, debió recurrir al apoyo de las fundaciones extranjeras, único medio de subsistencia disponible cuando la oferta de sus populares cursos se había vuelto inviable (Balbé, 1995) ${ }^{24}$.

En esas condiciones, el punto de apoyo principal de los centros fueron las fundaciones extranjeras que, sensibilizadas por el nuevo contexto dictatorial, decidieron redoblar sus esfuerzos en el país y en la región. Ese sostén fue clave para la supervivencia de los centros por los recursos materiales, pero también por la "protección" que la vinculación con reconocidas instituciones extranjeras ofrecía en el medio local. El aval de los centros era un reaseguro contra la caza de brujas que pesaba sobre los universitarios y académicos (Heredia, 2011). Si la labor de los centros se hallaba desde sus inicios conectada con la labor sociológica desarrollada en los centros mundiales de la disciplina, el contexto local reforzaba esa vinculación: la intensificación de la orientación hacia el exterior fue entonces asumida como una estrategia de supervivencia (Morales Martín y Algañaraz Soria, 2016) ${ }^{25}$.

Ahora bien, sin el contrapeso que las otras audiencias o clientelas habían ofrecido en el pasado, el trabajo de los sociólogos en los centros se volvía de modo inevitable más permeable y dependiente de las pautas o estilos promovidos por las fundaciones extranjeras. Si bien los investigadores no demoraron en encontrar algunas estrategias tendientes a eludir esas pautas -jugando con los márgenes que siempre existen entre la formulación de un proyecto y el desarrollo concreto de una investigación-, sus opciones y estilo de trabajo estuvieron fuertemente condicionados por quienes ofrecían el financiamiento. Por un lado, se privilegió el estudio de problemas de investigación más delimitados o acotados, que respondían mejor al formato de las convocatorias y a las expectativas de los evaluadores extranjeros que decidían la aprobación de los subsidios (Brunner y Barrios, 1987). Por el otro, se adoptaron unos criterios de evaluación y acreditación que, tal como ocurría en los centros mundiales de la disciplina, demandaban una creciente productividad. La acreditación constante de nuevas publicaciones y la necesidad de hacerlo en plazos más cortos devinieron una condición para acceder a nuevas oportunidades laborales. Como apuntan Brunner y Barrios, la "máxima norteamericana del "publish or perish"” asumió en los centros una particular traducción "el que no escribe no cobra" (Brunner y Barrios, 1987, p.157). Aun cuando sus miembros estuvieran ya socializados en la cultura del paper, las nuevas condiciones supusieron un ritmo de trabajo que no tenía precedentes. La autoexigencia fue en ese marco la contrapartida por recibir el apoyo desde el exterior (Morales Martín y Algañaraz Soria, 2016).

Pese a que a lo largo del período los recursos llegados desde el exterior no fueron escasos (Brunner y Barrios, 1987), la modalidad que asumió su asignación promovía en términos generales un clima de incertidumbre e inestabilidad, ya que los subsidios no estaban dirigidos al mantenimiento regular de los centros y sus investigadores, sino al financiamiento de proyectos de investigación puntuales a ser desarrollados en períodos no muy largos (que no solían superar los doce meses). Esos subsidios, por lo demás, no contemplaban gastos administrativos, capaces de facilitar la reproducción de esas instituciones. Bajo estas condiciones, no fue inusual que cada centro debiera "vivir al día", buscando eslabonar proyecto tras proyecto en una cadena que siempre amenazaba con romperse, y en la que ya antes de terminar una investigación había que plantear la 
siguiente con el fin de mantener un adecuado flujo de recursos ${ }^{26}$. En ese marco, no eran pocas las veces en que los sociólogos debían investigar temáticas que no siempre coincidían con sus intereses o inquietudes, pero que los posicionaban mejor frente a sus patrocinadores. La curiosidad intelectual o el compromiso político y social con ciertos temas debían dejar lugar al realismo impuesto por la propia supervivencia. Cabe aquí citar in extenso el relato de Catalina Wainerman, una de las fundadoras del Centro de Estudios de Población (CENEP), institución creada en 1974 a partir del trabajo de un conjunto de investigadores que habían debido dejar el ITDT a raíz de sus dificultades financieras. Refiriéndose a la gestión del CENEP, señala:

Nunca imaginé que hacerlo supondría adoptar un modo de vida, no sólo un medio de vida, en el que no hubo horarios, no hubo lujos, pero sí mucho, muchísimo trabajo y sacrificio, diseño de proyectos, presentación a subsidios, evaluaciones permanentes, calendarios estrictos, esperas angustiosas de resultados sin saber si sobreviviríamos económicamente o no, y no poder parar a festejar la obtención de un subsidio cuando ya había que empezar a diseñar el siguiente para mantener la cadena, es decir, el centro funcionando. Y todo esto en un país que no apreciaba ni buscaba ni consumía nuestra producción, que era sostenida desde fuera y para afuera. Muchas veces me sentí "el aprendiz de brujo" que no podía parar de hacer proyectos y proyectos para que el CENEP no sucumbiera, aun más allá de mis propias necesidades personales [Una] "aprendiz de brujo" que diseñaba proyectos, obtenía subsidios y producía informes (que terminaban en los archivos de las agencias subsidiantes, además de en algún artículo y/o ponencia) para escribir una nueva línea en mi currículum que aumentara las probabilidades de tener éxito en los próximos subsidios, sin transferencia a la sociedad (Wainerman, 2015, pp.116, 117).

Paralelamente, y como parte del mismo proceso, se dio una profundización de la influencia externa en el trabajo de los sociólogos de los centros, que debió orientarse cada vez más "hacia afuera", algo visible en la bibliografía y en los métodos utilizados -aquellos que se utilizaban en el exterior-, tanto como en los temas que investigaban -muchas veces más conectados con las agendas de fuera que con preocupaciones más locales- (Morales Martín y Algañaraz Soria, 2016). En un contexto que vedaba el acceso a audiencias más amplias y a la difusión libre de los resultados de las investigaciones, los centros debieron funcionar en buena medida como los enclaves de las economías coloniales, como espacios "modernizados" en estrecha conexión con el exterior, pero sin relación equivalente con el espacio social donde se insertaban. El trabajo debió asumirse en buena medida como un trabajo destinado a los pares (y evaluadores) extranjeros ${ }^{27}$.

Con todo, los sociólogos insertos en los centros no limitaron su labor al desarrollo de sus investigaciones sino que, en continuidad con lo que algunos de ellos habían realizado en los años previos, se embarcaron también en una intensa labor docente en diversas instituciones.

Por un lado, ofrecieron un variado conjunto de cursos y seminarios en los propios centros destinados en general a estudiantes avanzados o graduados preocupados por continuar su formación aun en el clima represivo vigente. Esos cursos no tenían un carácter masivo, lo que facilitaba la participación de sus alumnos como asistentes de investigación en alguno de los proyectos desarrollados en los centros, paso inicial de una carrera académica que aprovechaba las instancias más dinámicas disponibles en el campo local de las ciencias sociales.

Por otro lado, buena parte de ellos dio clases en el conjunto de espacios universitarios de enseñanza privada que, relativamente preservados de la injerencia o control estatal, continuaron en funcionamiento. Esos espacios habían surgido en los años previos, y fueron parte del movimiento de expansión e institucionalización de la disciplina iniciado en la segunda mitad de los años cincuenta (Germani, 2004; Noé, 2005). A las carreras creadas en las universidades confesionales -la Universidad Católica Argentina (UCA) y la Universidad del Salvador (USAL) - se habían ido sumando otras en la Universidad de Belgrano (UB), la Universidad de Kennedy y la Universidad Argentina de la Empresa (UADE). Sin embargo, el marco de extrema politización primero, y luego la desembozada hostilidad y represión para una disciplina tan identificada con la movilización estudiantil motivaron una reformulación de la oferta privada a partir de la cual fueron cerradas la mayoría de las carreras de grado en favor de una novedosa oferta de cursos de posgrado ${ }^{28}$. Así, al lado de la carrera de la USAL -la única de su tipo que permaneció en pie- se multiplicaron las maestrías y doctorados en sociología y ciencias sociales. Con ello las instituciones privadas 
apuntaban a cubrir un área de vacancia no explotada en nuestro país, con una oferta que, a diferencia de aquella movilizada por instituciones como el IDES y otros centros privados, gozaba de un aval oficial, pues se trataba de universidades en condiciones de emitir diplomas válidos ${ }^{29}$. Ahora bien, cabe señalar que en estas instituciones no se desarrollaban investigaciones, pese a que su cuerpo de profesores estaba integrado por sociólogos con una importante experiencia en el oficio. Ello era así porque las dedicaciones de los docentes eran de modo predominante dedicaciones simples. Así, aun cuando sus docentes pudieran enseñar metodología o desempeñarse como directores de tesis, sus labores vinculadas con la investigación se realizaban en los centros. La enseñanza y la investigación permanecieron en ese contexto escindidas.

Otro ámbito donde ejercer la docencia fue el Colegio de Graduados de Sociología (CGS), institución creada en 1975 como respuesta a las dificultades que la disciplina enfrentaba en el nuevo contexto represivo. Según el diagnóstico de sus impulsores, la organización colectiva de los sociólogos podría facilitar la jerarquización de sus saberes, su reconocimiento social y su inserción profesional, una cuestión particularmente problemática en un campo sociológico que se retraía. Una de las principales iniciativas del CGS fue la oferta de cursos que, por lo general, tenían un perfil "técnico", centrado en temas de metodología y técnicas de investigación o en temáticas más "aplicadas" (como la salud, la educación, el trabajo, etc.). Esos cursos resultaban particularmente atractivos para un público, muchas veces joven, preocupado por mejorar sus posibilidades laborales, fuera en la burocracia estatal, en el mundo privado. Para quienes habían estudiado en la carrera de la UBA en su período de máxima politización, y que, en consonancia con ello, habían desdeñado las materias metodológicas, la realización de esos cursos constituía una oportunidad para compensar lo que ahora veían como un "déficit" o "falla" en su formación ${ }^{30}$.

\section{ReFlexiones FinALES. El DESARrollo DE la SOCiOlogía EN las "CATACUMBas"}

La difusión de la persecución política y la represión a mediados de los años setenta produjo una profunda reorientación del escenario de la sociología argentina. El proceso de consolidación y diversificación institucional que la disciplina venía experimentando desde hacía un par de décadas, tanto como su creciente visibilidad en el campo intelectual y el espacio público, fue abruptamente interrumpido. El nuevo contexto, como vimos, motivó el cierre de varias carreras, el exilio de un buen número de sociólogos y la desaparición forzada de otros, la clausura de sus principales debates y la eliminación de las libertades mínimas que la práctica de la disciplina demandaba. En esas condiciones, la sociología se vio imposibilitada de poner en juego la vocación pública que había ostentado en los años anteriores, fuera en la visión "modernizadora" representada emblemáticamente por Germani, o fuera en la mirada crítica representada por quienes procuraron conectar la disciplina con el proceso de creciente politización. Lejos de ello, y sin posibilidades de vincularse con públicos o audiencias no académicas más amplias, los sociólogos debieron desarrollar sus labores de modo marginal, casi subterráneo. Mientras algunos animaban las "catacumbas" formadas por la red de centros y universidades privadas relativamente protegidas de la acción estatal, otros debieron moverse por las poco acogedoras "catacumbas" de la FDyCS.

Por un lado, quienes se hicieron cargo de la carrera de Sociología de la UBA - un conjunto de docentes que no siempre tenía una formación adecuada- debieron trabajar con escasos recursos, en un contexto de virtual aislamiento y bajo la permanente vigilancia de celadores y miembros de las fuerzas armadas. Es que lo que se hacía en la carrera, pese a las ilusiones de algunos profesores, no concitó demasiadas expectativas entre las autoridades gubernamentales, ni como foco de irradiación de ideas capaces de legitimar su proyecto político ni como brazo técnico capaz de ofrecer información y diagnósticos para las políticas públicas. Deseosos de los recursos materiales y simbólicos asociados a la docencia en la principal universidad pública del país, lo más importante que esos profesores consiguieron fue evitar el cierre de la carrera.

Por otro lado, quienes se insertaban en los centros privados de investigación pudieron continuar sus labores académicas, pero lo hicieron en el marco de una modalidad de trabajo crecientemente "ensimismada" 
y volcada "hacia afuera", cuya relevancia o pertinencia social no siempre resultaba clara para sus propios cultores. El reforzamiento de sus vinculaciones con las fundaciones y pares extranjeros, es cierto, les rindió recursos económicos y los preservó de la siempre amenazante intervención de las autoridades políticas. Pero también, sumado al contexto represivo, incrementó sus grados de dependencia académica y, en algunos casos, alentó una lógica de producción análoga a aquella propia de los enclaves económicos, más conectados con el exterior que con la sociedad donde se insertaban.

Las universidades privadas, por su parte, ofrecieron espacios de docencia que, como novedad, incluían ahora el nivel de posgrado. Sin embargo, al contar solamente con dedicaciones de tiempo parcial no se mostraron interesadas en estimular la investigación. De todos modos, su función docente, a la que se aunaron los cursos de los centros y del recientemente creado CGS, favoreció el perfeccionamiento de los sociólogos y otros profesionales en las destrezas propias de la disciplina. Gracias al accionar de estas instituciones, algunos jóvenes sociólogos -que luego ocuparían lugares destacados en el sistema académico-pudieron ser formados, aun en el marco de condiciones ciertamente adversas.

Ahora bien, el embate sufrido por la disciplina en los "años de plomo" no sería fácilmente revertido. El optimismo asociado a la recuperación de la democracia, cuya cara más visible fue la "refundación” de la carrera de Sociología de la UBA a partir de 1984, no fue suficiente. En ese caso, un nuevo cuerpo de profesores, varios de los cuales volvían del exilio, desplazó en su casi totalidad al heredado de la dictadura. Paralelamente, se produjo un aumento vertiginoso del número de estudiantes. Sin embargo, pese al entusiasmo inicial, esta institución no recuperaría la gravitación que en el pasado había tenido en el campo universitario e intelectual más general. Prueba de ello era que varias de las principales figuras de la sociología local decidían no reintegrarse a su cuerpo de profesores y los que lo hacían preferían hacerlo con una dedicación simple (de forma tal de poder participar en otras instancias más dinámicas de la escena intelectual). Aún más, las dedicaciones simples, aquellas que habían caracterizado a la carrera durante la dictadura, siguieron siendo mayoritarias, lo que conspiraba contra una mayor integración de la docencia y la investigación. Asimismo, la fragmentación del campo sociológico, con los centros privados funcionando sin una estrecha asociación con la carrera, continuaría casi sin cambios (Blois, 2009). Como vemos, tal como había ocurrido con la sociedad en general, el autoritarismo había producido en la sociología local una degradación material y simbólica de efectos duraderos.

\section{ReFERENCiAS}

Algañaraz, V. (2013). Between Scientific Autonomy and Academic Dependency: Private Research Institutes Under Dictatorship in Argentina (1976-1983). En F. Beigel (Ed.), The Politics of Academic Autonomy in Latin América (pp. 249-262). Londres: Ashgate.

Alvárez, E. (2006). Los intelectuales del "Proceso". Una aproximación a la trama intelectual de la última dictadura militar. Políticas de la Memoria, 6-7, 9-85.

Amadassi, E. y López Fidanza, J. (2011). La UCA y la Sociología en la UCA, desde sus inicios hasta nuestros días. Actas de las IX Jornadas de Sociología de la UBA, Argentina.

Apaza, H. (2008). Las Ciencias Sociales durante el terrorismo de Estado en Argentina. Actas de las V Jornadas de Sociología de la UNLP, Argentina.

Balbé, B. (1995). Somos militantes de la investigación. Entrevista con Beba C. Balvé. Dialéctica. Revista de Filosofía y Teoría Social, 7, 1-7.

Beigel, F. (2010). Autonomía y dependencia académica. Universidad e investigación cientifica en un circuito periférico: Chile y Argentina (1950-1980). Buenos Aires: Biblos.

Bekerman, F. (2009). El campo científico argentino en los años de plomo: desplazamientos y reorientación de los recursos. Sociohistórica, 26, 151-176. 
Bialakowsky, A. (1982). Espectro ocupacional del licenciado en sociología en el medio profesional argentino. Buenos Aires: Colegio de Graduados en Sociología.

Blanco, A. (2006). Razón y modernidad. Buenos Aires: Siglo XXI.

Blois, J. P. (2009). Sociología y democracia. La reorganización de la carrera de sociología en la UBA (1984-1990). Sociobistórica, 26, 111-150.

Blois, J. P. (2016). Profesión, compromiso y militancia. Las disputas por la definición de la sociología en la Argentina. Horizontes sociológicos, 8, 10-33.

Blois, J. P. (2017). La sociología como profesión en Argentina desde mediados del siglo XX. Cadernos de pesquisa, 47(165), 938-962.

Bonaldi, P. (2009). Aprendiendo sociología. Buenos Aires: La gomera.

Brunner, J. y Barrios, A. (1987). Inquisición, mercado y filantropia. Santiago: FLACSO.

Buchbinder, P. (2004). Historia de las universidades argentinas. Sudamérica: Buenos Aires.

Casco, J. (2008). El exilio intelectual en México. Notas sobre la experiencia argentina 1974-1983. Apuntes de investigación del CECyP, 13, 149-164.

Friedemann, S. (2016). Transición a la dictadura durante el gobierno de Isabel Perón. El ocaso de la Universidad Nacional y Popular de Buenos Aires. Entramados y perspectivas, 6, 3-36.

Friedemann, S. (2017). De las Cátedras Nacionales (1967-1971) a la Universidad Nacional y Popular de Buenos Aires (1973-1974). Experiencias configuradoras de institucionalidad universitaria. Sociobistórica, 9, 1-31.

Germani, A. (2004). Gino Germani. Del antifascismo a la sociología. Buenos Aires: Taurus.

Ghilini, A. (2011). Sociología y liberación nacional. La experiencia del grupo universitario de las Cátedras Nacionales. Question, 29.

Ghilini, A. (2017). Gino Germani: rebelión de sus discípulos e impugnaciones a la sociología científica. Nómadas, 46, 253-263.

Gil, G. (2011). Dilemas y conflictos en torno a la Fundación Ford en la Argentina de los '60. Revista Argentina de Sociología, 8-9(15-16), 153-181.

Heredia, M. (2011). Los centros privados de expertise en economía: génesis, dinámica y continuidad de un nuevo actor político en la Argentina. En S. Morresi y G. Vommaro (Comps.), Saber lo que se hace. Expertos y política en Argentina (pp. 297-338). Buenos Aires: UNGS.

Kirtchik, O. \& Heredia, M. (2015). Social and Behabioral Sciences under Dictatorship. In J. Wright (Ed.), International Encyclopedia of the Social Sciences (pp. 139-146). Oxford: Elsevier.

Lvovich, D. (2009). Sistema político y actitudes sociales en la legitimación de la dictadura militar argentina (1976-1983). Ayer, 75, 277-295.

Mallimaci, F., y Giorgi, G. (2007). Nacionalismos y catolicismos en la Facultad de Filosofía y Letras de la UBA. Actas de las VII Jornadas de Sociología de la UBA, Argentina.

Morales Martín, J., y Algañaraz Soria, V. (2016). Ciencias sociales, políticas de autonomía académica y estrategias de internacionalización en la última dictadura militar argentina (1974-1984). Revista Mexicana de Ciencias Politicas y Sociales, 61(227), 223-246.

Moscona, G. (2010). Peronismo e intelectuales: la experiencia de las Cátedras Nacionales en la UBA (Tesis de maestría). UBA, Facultad de Ciencias Sociales, Buenos Aires.

Motta, R. (2015). A política universitária da ditadura e as ciências sociais. En A. Alonso y M. Dohlnikoff(Orgs.), 1964 : do golpe a democracia (pp. 153-167). Sao Paulo: Hedra.

Neiburg, F. (1998). Los intelectuales y la invención del peronismo. Buenos Aires: Alianza.

Pereyra, D. (2010). Los científicos sociales como empresarios académicos. El caso de Gino Germani. En D. Pereyra (Comp.), El desarrollo de las ciencias sociales. Tradiciones, actores e instituciones en Argentina, Chile, México y América Central (pp. 35-53). San José: FLACSO.

Perel, P., Raíces, E., y Perel, M. (2006). Universidad y dictadura. Buenos Aires: CCC. 
Perlatto, F. (2013). Sociologia pública: Imaginação sociológica e problemas públicos (Tesis doctoral). Universidade do Estado do Rio, IESP, Rio de Janeiro, Brasil.

Raus, D. (2007). La sociología en el “Proceso". Sociología en Debate, 1, 16-25.

Rodríguez, L. (2015a). Universidad, peronismo y dictadura, 1973-1983. Buenos Aires: Prometeo.

Rodríguez, L. (2015b). Elites académicas durante la última dictadura: sociólogos e investigadores en ciencias sociales, Actas de las IX Jornadas de Sociología de la UNLP.

Rodríguez Bustamante, N. (1979). Sociology and reality in Latin America, the case of Argentina. International Social Science Journal, 31(86-97), 95-107.

Rubinich, L. (1999). Los sociólogos intelectuales: cuatro notas sobre la sociología en los '60. Apuntes de Investigación, 4,31-55.

Rubinich, L. (2010). Cómo relatar aquello que hacen los sociólogos. En L. Rubinich y G. Beltrán (Eds.), ¿Qué hacen los sociólogos? (pp. 9-53). Buenos Aires: Aurelia.

Sábato, H. (1996). Sobrevivir en dictadura: las ciencias sociales y la "universidad de las catacumbas. En H. Quiroga y C. Tcach (Comps.). A veinte años del golpe, con memoria democrática (pp. 51-57). Rosario: Homo Sapiens.

Seia, G. (2017). Los intentos de institucionalización y 'normalización' universitaria de la última dictadura. Debate universitario, 10, 8-30.

Sidicaro, R. (1993). Reflexiones sobre la accidentada trayectoria de la sociología en la Argentina. Cuadernos Hispanoamericanos, 517-519, 65-76.

Suárez, F. (1973). Algunas reflexiones sobre los procesos de institucionalización de la Sociología en la Argentina. Revista Mexicana de Sociología, 35(1), 117-134.

Trindade, H. (2007). Las ciencias sociales en América Latina en perspectiva comparada. México: Siglo XXI.

Wainerman, C. (2015). La trastienda de la investigación social. Acerca de la "ñata contra el vidrio". Ciencia e Investigación, 3(1), 110-123.

\section{Notas}

1 El foco principal de las críticas de las "cátedras nacionales" se había orientado en una doble dirección. Por un lado, contra la idea de la sociología como una "profesión” que debía estar preservada de las disputas ideológicas con base en una decidida "neutralidad valorativa". Por el otro, contra el sesgo "importador" (de ideas, conceptos, metodologías) que, en su visión, Germani y el "cientificismo" en general le habían dado a la disciplina (Blois, 2016; Ghilini, 2011; Moscona, 2010).

2 En los años previos la cuestión laboral había suscitado acalorados debates. Destacadas figuras como Germani, Adolfo Critto, Torcuato Di Tella o Manuel Mora y Araujo habían alentado la participación de los sociólogos en el Estado y otras instituciones, promoviendo una concepción de la disciplina que debía evitar el estricto "academicismo" en pos de la resolución de problemas sociales “concretos e inmediatos". Sin embargo, la creciente politización y las expectativas sobre una posible transformación radical de la sociedad no ofrecieron el marco más receptivo para esas ideas. Fueron moneda corriente entonces los discursos que denunciaban al “tecnócrata” y la pretensión de una expertise sociológica neutral. Así, figuras tan distantes como Roberto Carri y Eliseo Verón coincidían en que la elaboración de "recetas técnicas” para la intervención estatal sólo contribuiría a aliviar las tensiones sociales y preservar un orden injusto (Blois, 2016; 2017).

3 El aliento a la incorporación de los sociólogos al Estado no conllevaba, con todo, una apertura equivalente hacia el trabajo en el mundo privado. Lejos de ello, la inserción en las empresas continuó suscitando una fuerte censura, reforzada ahora por las propias autoridades de la UBA quienes establecieron la incompatibilidad de la docencia universitaria con el "desempeño de funciones -jerárquicas o no- al servicio de empresas multinacionales o extranjeras" (Buchbinder, 2005, p. 203).

4 Algunas de ellas, sin embargo, cambiaron de nombre Historia Social, por ejemplo, fue reemplazada por Historia de los países imperialistas (siglo XX) e Introducción a las Ciencias Politicas fue rebautizada como Sociología del poder.

5 La identificación directa con el peronismo y su gobierno no era menor entre los jóvenes graduados de la carrera que se hacían cargo por primera vez de una materia. Así, por ejemplo, Aníbal Jozami planteaba en "Dialéctica de la dependencia y la liberación en la historia argentina" que la ciencia social debía estar "subordinada" y ser "dependiente de la política en tanto expresión del más alto nivel de conciencia”. La materia se proponía analizar las diversas experiencias que 
en el pasado habían buscado la "destrucción del liberalismo capitalista" (aquellas de 1810, 1837-1952, 1916-1930 y 1943-1955) para llegar al momento actual signado por la "ubicación geopolítica de la Argentina, en los términos enunciados por el Conductor del Movimiento Peronista como integrante del Tercer Mundo, cuya realización se contradice antagónicamente con el Imperialismo".

6 Distintos observadores han señalado que la "politización" de la sociología impulsada por las "cátedras nacionales" puede ser entendida como una iniciativa tendiente a legitimar sus posiciones en sus disputas con los sociólogos "cientificistas”. En este sentido, según Sidicaro, ese accionar debe ser visto a la luz de lo que Bourdieu denomina estrategias de subversión, "recurso habitual empleado por quienes quieren entrar en un campo cultural específico sin poseer el suficiente capital legítimo, según los patrones vigentes en el momento” (Sidicaro, 1993, p. 70). Ahora bien, lo particular de este caso es que quienes empleaban semejantes estrategias lo hacían asumiendo un "ropaje antiacademicista" que implicaba la virtual puesta en cuestión del propio espacio que estaba siendo disputado (Rubinich, 1999). Así, aun cuando estos sociólogos pudieran pasar lo esencial de su tiempo en la universidad, su prédica constante apuntaba contra las limitaciones propias de la vida académica y la reivindicación de una praxis directamente política.

7 Según datos del censo universitario, los alumnos de Psicología superaban los 7000 y los de Sociología eran casi 2800, seguidos por los de Ciencias de la Educación con casi 1200. Por su parte, los de Letras, la más numerosa entre las carreras tradicionales, no superaban los 1300, mientras que los de Filosofía tenían poco más de 1000, los de Historia no llegaban a los 750 y los de Geografía eran pocos más de 200 (censo UBA). Entre los considerandos que fundamentaban el desmembramiento de la Facultad se señalaba que el "incremento y autonomía adquirido por estas carreras (Sociología, Psicología y Ciencias de la Educación, así como) su heterogeneidad epistemológica y metodológica en relación con la naturaleza humanística de las carreras arquetípicas y tradicionales de esta Facultad [impedían] cimentar y ejercitar con los métodos apropiados y los medios necesarios su desarrollo académico" (en Actas del Consejo de la FFyL, UBA, 27/10/1974).

8 Desde su fundación, el aumento del número de estudiantes y de su cuerpo docente había superado con creces la ampliación del espacio físico disponible. Al respecto, puede verse Bonaldi (2009), especialmente pp. 58-60.

9 Según señala Rodríguez, diferentes autoridades del área educativa sostuvieron la necesidad de cerrar las carreras de Sociología en el país. En algunos casos, como ocurría con el ministro de Educación Ricardo Bruera, se recomendaba su reconversión como carreras de posgrado; en otros, como ocurría con el secretario de Educación de la Nación, el contraalmirante Enrique Carranza, simplemente su clausura. Este tipo de prédica halló eco en algunas universidades del interior. En la Universidad Nacional de Mar del Plata y en la Universidad de Cuyo las carreras fueron cerradas (Rodríguez, 2015a).

10 En ese intervalo fueron convocados algunos llamados a exámenes finales con la idea de facilitar la graduación de aquellos que, con un grado de avance importante, se habían quedado sin la posibilidad de terminar sus estudios.

11 Una muestra adicional del escaso interés que despertaba la carrera fue el hecho de que la ola masiva de concursos que se produjo a partir de 1980 con el fin de "normalizar" los cambios que se habían venido desarrollando en la UBA no incluyó a Sociología, cuyo cuerpo docente mantuvo en su casi totalidad una contratación interina (Seia, 2017). Ello facilitaría su casi total remoción a partir de 1984 (Blois, 2009).

12 Tanto Roberto Brie como Fernando Cuevillas formaban parte del grupo de sociólogos católicos y nacionalistas que llegaron a la carrera a partir de la intervención de 1966. El primero, un padre jesuita que había abandonado los hábitos para desarrollar una carrera académica (que incluía la realización de un doctorado en filosofía en la Universidad de Friburgo), llegó a ser designado director del Departamento de Sociología en 1968. Cuevillas, un abogado católico vinculado a la llamada "sociología de cátedra", ocupó por su parte esa posición en 1969 y se hizo cargo de la dirección del Instituto de Sociología entre 1970 y 1971. Sin dudas, la presencia de esos sociólogos había planteado una curiosa convivencia en el seno de la carrera entre orientaciones ideológicas muy disímiles, con una mayoría de estudiantes y docentes volcados a la izquierda y un conjunto de profesores vinculados a las redes intelectuales que apoyaban la gestión de Onganía.

13 Roberto Brie fue una figura central en el armado del plantel docente. Si bien permaneció sólo un año dando clases, fue clave en la llegada de un conjunto de jóvenes sociólogos que, vinculados a los círculos católicos y nacionalistas, lo reconocían como su "maestro". Entre ellos, Norberto Ianelli, un graduado de la UCA que se hizo cargo de Sociología General I; Osvaldo Scassera, también un graduado de la UCA que dictó Sociología General II, y Enrique Pistoletti, un graduado de la UBA que se hizo cargo de Sociología III y de Introducción a la Sociología. Cabe señalar que a partir de 1976, y aprovechando una coyuntura signada por la "depuración” de las instituciones oficiales (Bekerman, 2009), Brie pudo acceder a algunas posiciones encumbradas del sistema de ciencia nacional (fue nombrado miembro del directorio del CONICET y funcionario de la UNESCO). Ello le granjeó el acceso a ciertos recursos financieros que destinó a la formación de un conjunto de centros de investigación en ciencias sociales -luego denunciados como parte de maniobras fraudulentas por el propio CONICET (Sábato, 1996)-, y a la edición de una revista de ciencias sociales llamada Sociológica en la que varios de los integrantes de la carrera publicaban sus trabajos. Sobre la revista Sociológica, Cf. Apaza (2008) y Rodríguez (2015b). 
14 Cabe mencionar, en este sentido, la presencia breve en la carrera (de un solo cuatrimestre) de José García Venturini, un filósofo que había alcanzado una cierta visibilidad pública gracias a sus constantes apariciones en la prensa y los medios de comunicación masiva y que durante esos años se desempeñaba como presidente de Eudeba (Invernizzi y Gociol, 2003).

15 Según nota Rodríguez (2015b), la falta de referencias a los trabajos realizados en los centros privados de investigación fue también una constante en la revista Sociológica.

16 Sólo Osvaldo Verón, un joven graduado de la carrera, quien en 1973 había estado a cargo de Introducción a la Ciencia Política, proponía en Sociología General II un uso intensivo de esa bibliografía: a los textos de Butelman, Graciarena, Sautu y Germani, les sumaba traducciones de autores como Davis, Durkheim, Gerth y Mills, Lazarsfeld, Lewin, Parsons, entre otros.

17 Llegados a la carrera a partir de la intervención de 1966, estos sociólogos fueron rápidamente identificados como "sociólogos del régimen", suscitando, de acuerdo a testimonios de la época, diversas formas de resistencia entre los estudiantes: desde la baja inscripción a sus materias hasta la organización de protestas tendientes al establecimiento de cátedras paralelas, pasando por la rendición de los exámenes en forma libre (algo que al tiempo que evitaba la presencia en las clases de esos profesores, permitía continuar la cursada). Su denuncia era frecuente en los panfletos distribuidos por las agrupaciones estudiantiles.

18 La única excepción era Los que mandan de José Luis de Ímaz, sociólogo católico formado por Germani que se había desempeñado como asesor del gobierno de Onganía.

19 Hubo, con todo, un conjunto de materias muy heterogéneas que abordaban algunas cuestiones más actuales y “concretas". Así, en Psicología Social, Santiago Valdés ofrecía una unidad sobre "opinión pública”, que incluía una presentación sobre las formas de su medición, y otra sobre "Propaganda y publicidad" centrada en los estudios del consumidor y la "investigación motivacional”; en Ecología social, Rolando Gioja enseñaba temas de planificación; en Geopolítica, el capitán de fragata (re) Juan José Allegroni incorporaba una última bolilla sobre la "cuestión del Beagle”, problemática muy actual en aquel momento.

20 Semejante orientación de las autoridades militares contrastaba de modo marcado con la situación vivida en Brasil donde, aun en el marco de una extendida represión contra los intelectuales asociados a la izquierda, se desarrolló una política académica modernizadora que amplió fuertemente los recursos disponibles para las tareas de investigación en las universidades. Cabe destacar que si bien la enorme mayoría del financiamiento fue destinada a las áreas tecnológicas y a las ciencias naturales, las ciencias sociales pudieron beneficiarse del crecimiento generalizado de la infraestructura institucional para la docencia y la investigación (Motta, 2015). El caso de Brasil, donde el nivel de posgrado inicia una clara expansión, se distancia, en ese marco, de otros países del Cono Sur.

21 Cabe señalar que esas restricciones -entre las que se destacaban la reincorporación del examen de ingreso, el pago de un arancel y el establecimiento de cupos por carreras- tuvieron un fuerte impacto en la matrícula de la UBA. Mientras el número de nuevos estudiantes en 1974 había superado los 40 mil, en 1977 la cifra se había reducido a poco más de 13 mil (Buchbinder, 2004).

22 Según recordaba Inés Izaguirre, cuando en 1978 Juan Carlos Marín presentó una primera versión de lo que luego sería su libro Los hechos armados suscitó entre sus pares un extendido rechazo hacia él y el CICSO, institución donde había desarrollado la investigación. "Tuvo un costo muy alto, pues casi todos los centros de Buenos Aires nos tildaron de 'locos' y se apartaron de nosotros como de la peste. El IDES nos pidió que retiráramos nuestras publicaciones de allí. Un gran amigo mío [vinculado al CISEA] tuvo una entrevista conmigo para decirme si habíamos pensado lo que hacíamos, pues habíamos puesto en riesgo a toda la comunidad de ciencias sociales. Yo le hice ver que el libro hablaba del 73-76, no de los milicos, cosa que ni siquiera se había dado cuenta, tal era su pavor" (Izaguirre citado en Santella, 2000, p. 7).

23 El Instituto de Desarrollo Económico y Social (IDES), institución fundada en 1960, había tenido como una de sus principales iniciativas la formación de recursos humanos a través de la oferta de seminarios para graduados y profesionales en las áreas de economía, historia, sociología y metodología. Dado el escaso desarrollo del posgrado en el medio local, esos cursos se convirtieron en una referencia para los sociólogos que quisieran continuar sus estudios luego de terminada su carrera. Si bien los cursos no tenían validez oficial pues el Estado no le reconocía al IDES la capacidad de otorgar títulos, su realización no dejaba de gravitar como un valioso antecedente a la hora de proyectar una carrera académica y profesional.

24 Los cursos del CICSO habían buscado ir más allá del público especializado al que apuntaban instituciones como el IDES, procurando conectar más directamente con el proceso de politización en marcha. Para ello, además de dirigir sus esfuerzos a captar el interés de los estudiantes de las carreras de sociología y de los jóvenes graduados, abrió sus puertas a todos aquellos que, sin la intención de hacer de las ciencias sociales una profesión, veían en ellas una forma de ampliar sus horizontes culturales y/o de cultivar sus inquietudes políticas (Balbé, 1995).

$25 \mathrm{Al}$ accionar de las fundaciones norteamericanas, se sumaron las iniciativas de un conjunto de agencias de cooperación de gobiernos de países europeos que concebían el apoyo a las ciencias sociales como una forma de resistir y cuestionar a los regímenes militares instalados en la región (Heredia, 2011). 
26 Semejante modalidad de los subsidios reforzaba el ascendiente que las fundaciones tenían sobre los investigadores locales y generaba un profundo malestar. La crítica al financiamiento por proyecto fue, de hecho, moneda corriente en esos años entre los centros de la región que reclamaban un tipo de apoyo más flexible, de mayor duración y con un componente destinado a reforzar su funcionamiento institucional. Ello, además de ampliar sus márgenes de autonomía, permitiría, según aducían, evitar la compleja -y "creativa” - ingeniería contable a la que se veían llevados por unas convocatorias que no financiaban rubros indispensables para el desarrollo de sus labores (gastos administrativos, personal de apoyo, alquileres, etc.) (Brunner y Barrios, 1987).

27 Esa situación contrastaba fuertemente con lo ocurrido en otras latitudes. Así, en Brasil, por ejemplo, los centros de investigación privados, surgidos también como respuesta a la intervención militar en las universidades a partir del golpe de 1964, pudieron desarrollar una agenda de investigación fuertemente conectada con los temas más candentes de la coyuntura social y política, asumiendo incluso desde sus mismos orígenes un rol central en la oposición al régimen militar y en los debates y polémicas en torno al retorno a la democracia. Cabe recordar aquí, en este sentido, las relaciones que el Centro Brasileiro de Analise e Planejamento (CEBRAP) mantuvo con sectores de la Iglesia Católica, institución de fuerte gravitación en la oposición y cuestionamiento del régimen vigente, así como los vínculos que algunas de sus figuras entablaron con el naciente Movimiento Democrático Brasileiro (MDB). Del mismo modo caben mencionar las relaciones del Centro de Estudos de Cultura Contemporânea (CEDEC) con el movimiento obrero y la participación de algunos de sus intelectuales en la fundación del Partido dos Trabalhadores (PT) (Motta, 2015; Perlatto, 2013).

28 Las carreras de la UCA y la USAL no habían permanecido al margen del proceso de activación política en el período anterior, siendo frecuentes los conflictos entre las perspectivas más radicalizadas de estudiantes y parte de los docentes y la visión más conservadora de las autoridades universitarias (Amadassi y Fidanza, 2011; Suárez, 1973).

29 Cabe mencionar aquí también la maestría en Ciencias Sociales inaugurada por la FLACSO en 1979, espacio que acogió a un buen número de estudiantes (Morales Martín y Algañaraz Soria, 2016).

30 La preocupación por la inserción profesional fue tal que el CGS encargó la realización de una encuesta sobre el "espectro ocupacional del licenciado en sociología”, la primera de su alcance en el país. Lejos de las miradas críticas que en el pasado habían cuestionado la configuración de la disciplina como una "profesión”, el CGS cuestionaba la politización extrema de la disciplina, vista ahora como un "desajuste" que podía llevar "al extrañamiento (alienación) del rol específico" del sociólogo (Bialakowsky, 1982, p. 4). Las dificultades del nuevo contexto promovían una visión más acotada -y modesta quizá- sobre el papel social de los sociólogos (Blois, 2017). 